\title{
O golpe nosso de cada dia: as mui familiares ameaças aos direitos dos povos indígenas no contexto do impeachment
}

L Bruno Martins Morais

Universidade de São Paulo, São Paulo, São Paulo, Brasil

DOI 10.11606/issn.2316-9133.v25i25p42-45

Não havia menção à Funai na medida provisória que reorganizou a Esplanada dos Ministérios logo no primeiro dia em que Temer assumiu a Presidência, ainda como interino. Uma comitiva de lideranças indígenas foi bater à porta do recém-empossado ministro da Justiça, Alexandre de Moraes, e ouviu um pedido de desculpas: seria "mero erro de redação". Mas corria na imprensa a notícia de que a Casa Civil concentraria os órgãos da política fundiária - o governo havia recuado, portanto? ${ }^{1}$ A imprensa alardeava que as demarcações realizadas ao final do governo Dilma seriam anuladas, Alexandre de Moraes negou peremptoriamente - o governo havia recuado, portanto ${ }^{2}$

A política indigenista de Temer parece estar sendo desenrolada no improviso, ou na maldade. ${ }^{3}$ Em que pese a negativa do ministro, em dezembro do ano passado (2016) foram devolvidos à Funai pelo menos vinte procedimentos de terras que aguardavam portarias declaratórias e decretos de homologação. Na mesma época, a Folha de S.Paulo publicou uma minuta de decreto com um novo marco regulatório do procedimento de demarcação de terras indígenas, incluindo como regra a tese do marco temporal: apenas as áreas efetivamente ocupadas na data de promulgação da Constituição, 5 de outubro de 1988, seri-

\footnotetext{
${ }^{1}$ Com efeito, cinco pastas responsáveis pelas políticas de reforma agrária do governo federal, entre as quais a Secretaria Especial de Agricultura Familiar e do Desenvolvimento Agrário, foram transferidas para a Casa Civil já em maio. Cf. Temer transfere Incra e secretarias da reforma agrária para a Casa Civil. Portal G1, 30 mai. 2016. Disponível em: <http://g1.globo. com/politica/noticia/2016/05/temer-transfere-incra-e-secretarias-da-reforma-agraria-paracasa-civil.html>. Acesso em: 28 fev. 2017.

${ }^{2}$ Temer diz a ruralistas que vai revisar desapropriações e demarcações. O Globo, 30 abr. 2016. Disponível em: <http://oglobo.globo.com/brasil/2016/04/30/3046-temer-diz-ruralistas-quevai-revisar-desapropriacoes-demarcacoes $>$. Acesso em: 18 fev. 2017.

3 "Maldade" e "improviso" são palavras de Adriana Ramos, coordenadora do Programa de Política e Direito Socioambiental, em análise publicada pelo El País. Cf. Entre o improviso e a maldade: a política (anti-)indigenista do Governo Temer. El País, 24 jan. 2017. Disponível em: <http://brasil.elpais.com/brasil/2017/01/24/opinion/1485269600_994030.html>. Acesso em: 28 fev. 2017.
} 
am passíveis de ser demarcadas. ${ }^{4} \mathrm{~A}$ aplicação da tese, tal qual, anularia $80 \%$ dos procedimentos demarcatórios em aberto no país, sobretudo fora da Amazônia, onde a expansão do agronegócio expropriou as terras dos índios entre a década de 1940 e 1980 . O ministro, no entanto, veio novamente a público negar que havia qualquer disposição do governo em alterar o decreto $n^{\circ}$ 1775/96.

E novamente, apesar da negativa, em janeiro deste ano (2017) foi publicada uma portaria que criava um "Grupo Técnico Especializado" com poderes para reavaliar os processos de demarcação em andamento e observar o "cumprimento da Jurisprudência do Supremo Tribunal Federal". ${ }^{5}$ A portaria poderia produzir os mesmos efeitos que uma mudança no procedimento demarcatório via decreto e teria a vantagem de aparentar constitucionalidade. Reações do movimento indígena, indigenista e do Ministério Público Federal parecem ter surtido efeito: o dispositivo foi substituído no dia seguinte por um texto mais enxuto, reduzindo as atribuições do grupo técnico - improviso ou maldade? ${ }^{6}$

Na mesma edição que publicava a portaria, o Diário Oficial da União trazia a nominação à presidência da Funai de Antonio Fernandes Toninho Costa, um dentista e pastor evangélico indicado pelo Partido Socialista Cristão (PSC). Desde o segundo semestre do ano passado, pelo menos três pessoas já haviam anunciado publicamente a sua indicação à presidência do órgão. Entre as especulações, a de maior corpo era a de dois generais; mas a nomeação de um militar à chefia da Funai cheirava demasiado à ditadura para que passasse desapercebido ao movimento indígena. Pressão contra o Ministério da Justiça resultou na recusa em militarizar a presidência, mas não impediu que o Gen. Franklinberg fosse nomeado diretor de promoção ao desenvolvimento sustentável, a pasta que tem competência sobre o licenciamento ambiental. Desse modo, a esplanada garantiu controle militar sobre a incidência do órgão em obras de impacto. ${ }^{7}$

Já Toninho Costa inaugurou seu mandato em turnê ao Mato Grosso do Sul. Reuniu-se com representantes das federações agropecuárias, sentou com usinei-

\footnotetext{
${ }^{4}$ Documento do governo altera regra para demarcar terra indígena. Folha de S.Paulo, 12 dez. 2016. Disponível em: <http://www1.folha.uol.com.br/poder/2016/12/1840543-documentodo-governo-altera-regra-para-demarcar-terra-indigena.shtml>. Acesso em: 19 fev. 2017.

${ }^{5}$ Ministro da Justiça altera demarcação de terras indígenas no país. Folha de S.Paulo, 18 jan. 2017. Disponível em: <http://www1.folha.uol.com.br/poder/2017/01/1851036-ministro-da-justicaaltera-demarcacao-de-terras-indigenas-no-pais.shtml>. Acesso em: 19 fev. 2017.

${ }^{6}$ Ministro revoga própria norma sobre demarcação de terras indígenas. Folha de S.Paulo, 19 jan. 2017. Disponível em: <http://www1.folha.uol.com.br/poder/2017/01/1851456-ministrorevoga-propria-norma-sobre-demarcacao-de-terras-indigenas.shtml>. Acesso em: 19 fev. 2017. ${ }^{7}$ Em tempo, após uma queda de braço com o então Ministro da Justiça Omar Serraglio (PMDB), Antonio Toninho Costa foi demitido em maio de 2017 e, na imprensa, acusou a ingerência da bancada ruralista no órgão. Cf. Deixo a Funai por não ceder a ingerências políticas, diz Toninho Costa. Valor Econômico, 05 maio 2017. Disponível em: <http://www.valor.com.br/ politica/4958910/deixo-funai-por-nao-ceder-ingerencias-politicas-diz-toninho-costa>. Acesso em: 05 jul. 2017. Em seu lugar, como presidente da Fundação, foi finalmente nomeado o Gen. Franklimberg Ribeiro de Freitas.
} 
ros e defendeu a criação de um fundo que viabilizasse as demarcações com indenização aos pretensos proprietários de títulos incidentes sobre terras indígenas. Em entrevista, criticou o assistencialismo da fundação: "temos que produzir sustentabilidade", disse, sem explicar como pretende "ensinar os índios a pescar" (!) diante da redução radical do orçamento da instituição. ${ }^{8}$ A ONG Survival International publicou nota em dezembro de 2016 acusando a previsão orçamentária da fundação para o ano de 2017 de estar defasada em catorze anos. ${ }^{9}$

O governo improvisa ou malfaz as politicagens de corredor. $\mathrm{O}$ futuro da instituição, do marco legal do procedimento demarcatório, do indigenato, enfim, seguem incertos mas mal-agourados. Por sobre tudo isso, uma Comissão Parlamentar de Inquérito supostamente implantada para investigar irregularidades na demarcação de terras indígenas e quilombolas pela Funai e Incra, respectivamente, encerrou os seus trabalhos recomendando o indiciamento de 67 pessoas. Entre elas, lideranças comunitárias acusadas de falsidade ideológica por identificarem-se como indígenas ou quilombolas; antropólogos e indigenistas, acusados de forjarem os relatórios de identificação e delimitação de terras; e mesmo acadêmicos, pesquisadores da Universidade Federal de Santa Catarina e do Museu Nacional, associados à associação da classe. Medidas judiciais estão sendo preparadas na tentativa de evitar que essas pessoas respondam acusações criminais pela prática do ofício antropológico; ou, pior, por sua identidade étnica.

O sentimento geral é de derrota. Não creio que haja entre nós, a essa altura, alguém que não se sinta como se tivesse perdido algo. Talvez a inocência. Talvez a esperança. Esse sentimento não deixa dúvidas de que o impedimento da presidenta eleita bambeou a corda da democracia - por que, então, os espectros que rondam o pós-golpe nos são, assim, tão familiares? A enumerar: a fragilidade da Funai; a carência de perspectivas no andamento das demarcações; os discursos defendendo mudanças no procedimento demarcatório; as minutas de decreto; os avanços no Legislativo e no Judiciário das teses mais conservadoras e contrárias ao indigenato, enfim, todas essas mais sérias ameaças aos direitos dos povos indígenas no contexto do golpe chegaram à esplanada e assentaram nos corredores dos ministérios, do Congresso Nacional, durante a democracia do Partido dos Trabalhadores (PT). A mesma democracia que agora impera defender?

O "golpe", penso, é uma oportunidade para autocrítica. No momento em que a estimativa de propina envolvida na construção da hidrelétrica de Belo Monte bate à casa dos 120 milhões de reais, já não creio que haja muito a ser dito sobre a política dos últimos dez anos: capitulamos, mediamos, compusemos, e de al-

\footnotetext{
${ }^{8}$ Nova Funai quer índios produtivos. Valor Econômico, 13 fev. 2017. Disponível em: <http://www. valor.com.br/brasil/4866768/nova-funai-quer-indios-produtivos>. Acesso em: 18 fev. 2017.

${ }^{9}$ Corte de orçamento na Funai pode ameaçar tribos isoladas, diz ONG. Portal G1. Disponível em: <http://g1.globo.com/ac/acre/noticia/2016/12/corte-de-orcamento-na-funai-pode-ameacartribos-isoladas-diz-ong.html>. Acesso em: 18 fev. 2017.
} 
gum modo somos também responsáveis por as coisas haverem chegado aonde estão. Importante é lembrar, contudo, que houve nesse tempo os que fincaram o pé no chão. Por ora, Michel Temer ensaia, mas ainda não mostrou a que veio na política indigenista. Os ventos do impeachment parecem ter reanimado os tratores do progresso; e os custos sociais, sabemos, pagam primeiro os índios, os que fincam o pé no chão.

Apesar desses pesares, os Guarani têm o que comemorar neste começo de ano: no dia 27 de janeiro de 2017 foi publicada a identificação da TI Pindoty/ Araçá-Mirim (SP), a primeira delimitação de terra ratificada por um presidente da Funai indicado por Michel Temer. ${ }^{10} \mathrm{~A}$ escola da última década parece, em alguma medida, tê-los preparado para o golpe nosso de cada dia.

Nós, sim, é que ainda temos muito o que aprender com eles.

autor Bruno Martins Morais

Advogado e Mestre em Antropologia Social pelo PPGAS/USP. Assessor jurídico do Centro de Trabalho Indigenista e da Comissão Guarani Yvyrupa.

Recebido em 20/02/2017 Aceito para publicação em 20/02/2017

\footnotetext{
${ }^{10}$ Terra Guarani é identificada pela Funai. Instituto Socioambiental, 27 jan. 2017. Disponível em: <https://www.socioambiental.org/pt-br/noticias-socioambientais/terra-guarani-eidentificada-pela-funai>. Acesso em: 18 fev. 2017.
} 